\title{
On the Issue of Polite Appeals and Blessings in Indian English
}

\author{
Elena Kurchenkova $^{1, *}$, Irina Palashevskaya $^{1}$, Maria Kurchenkova $^{1}$ \\ ${ }^{1}$ Philology and Intercultural Communication, Department of German and Romance Philology, Volgograd State University, 100, \\ Universitetskiy av., 400062, Volgograd, Russia.
}

\begin{abstract}
The primary purpose of this study is to investigate politeness as the culture-specific phenomenon, the actual manifestations of it in the Indian version of English. The study distinguishes some politeness fixed formulae in Indian English on the basis of the Speech Acts theory. It focuses on such culturally determined politeness patterns in Indian English as appeals and blessings, their functions and language features as compared with the ones in the standard version of British English. The use of polite appeals and blessings in Indian English is greatly influenced by age and gender restrictions and a traditional family structure with a Patrilineal background which has been followed since long ago. The choice of appeals and blessings in social interactions mainly depends on their basic strategies as speech acts. The study shows the points where two different lingua-cultures never meet.
\end{abstract}

\section{Introduction}

In all human speech societies, there are fixed formulae of politeness, such as greetings, farewells, expressions of gratitude, apologies, compliments, performed in everyday interactions in a wide range of social situations. Ch. Ferguson suggests that people have "innate predispositions to the use of interjections and ritualized exchanges in which a given formula triggers an automatic response» [1]. An adequate response to a certain formula of politeness is an obligatory linguistic competence and is included in the process of education of a highly cultural personality while teaching both native and foreign languages.

\subsection{Application of Speech Acts Theory}

Problematic issues of interrelations of the speaker and the listener, the addresser and the addressee find their solutions in the theory of speech acts. This theory offers its original model of communicative situation [2]. Along with such components as a speaker, listener, utterance, it includes the purpose and the effect of speech acts.

J. L. Austin in his book "How to Do Things with Words" considered typical examples of speech acts and named them. Also, he notes that each language has a different variety of such speech acts [3].

In any speech act, J. L. Austin distinguishes three levels: the locutionary, the illocutionary and the perlocutionary acts. Performing a locutionary act, the speaker simultaneously performs an illocutionary act when he asks or answers a question; informs, persuades or warns; announces a decision or intention; announces the verdict; appoints, calls or criticizes; identifies, describes, thanks, etc. The perlocutionary act is considered as a part of a speech act of the speaker, and not the reciprocal (speech or non-verbal) action of the addressee. Perlocution is understood as the impact on the informational and psychological state of the addressee, on his mood, plans, desires and will. But if the addressee answers or does not consider it necessary to answer, it is beyond the initiative speech of the speaker.

Great place in the theory of J. L. Ostin is given to performative speech act. A performative enters the context of life events, creating a social, communicative or interpersonal situation that entails certain consequences (for example, declarations, wills, oaths, apologies, administrative and military orders, etc.). Saying "I swear" means to bind oneself with an oath. The corresponding performative action is performed by the speech act itself. So, the oath is impossible without pronouncing its text. In this sense, performatives indicate the action they perform themselves. In the performative speech act any language implements a function close to the magic (ritual), cf. acts such as naming objects, and blessings.

\subsection{Classification of Speech Acts}

The most famous universal classification of illocutionary acts is made by American philosopher J. R. Searle in his work "Classification of Illocutionary Acts" [4], where he distinguishes five groups of speech acts: representatives, directives, commisives, expressives, declaratives. The basis of this classification is a group of characteristics, which the author calls "the dimensions of variations" between the illocutionary acts. The most significant of them are:

- the purpose (for the speech act of order - to persuade the addressee to act, for the promise - to commit it, for the congratulation - to express a certain emotion of the speaker);

\footnotetext{
* Corresponding author: kurlena@volsu.ru
} 
- the direction of the correspondence between the utterance and reality (in the case of a message, the utterance is brought into accordance with the reality, in the case of an order, the reality must be brought into accordance with the statement);

- internal state of the speaker (for example, for affirming - he or she must have a corresponding opinion, for a promise - intentions, for thanksgiving - feelings of gratitude);

- features of the propositional content of the speech act (in the prediction, it refers to the future of the time, and in the report - to the present or the past);

- connection of a speech act with extralinguistic institutions (for example, a speech act of appointing someone as his deputy is usually drawn up in the form of a document).

Classification in accordance with the communicative purpose of the speaker was represented by G.G. Pocheptsov, who distinguishes five classes of text (informatives, directives, expressives, commissives, occultives), and each class is characterized by the basic speech functions [5]. In addition, G.G. Pocheptsov indicates the existence of phatic (meta-communicative) speech acts that implement the contact-determining function of the language [6]. Phatic speech acts can be regarded as a basic class for better analysis of speech acts of blessing.

According to G.G. Pocheptsov and J.R. Searle, the directive type of speech acts corresponds to the units with the regulating function. Directives are speech acts used by the speaker to induce the hearer to perform a certain action; these include such subtypes as orders, requirements, requests, prayers, invitations, advice, recommendations, instructions, questions.

The expressive type of speech act corresponds to units where the influencing function predominates. Expressives are the acts manifesting the author's psychological state, including formulas of social etiquette.

We consider the following functional types of speech acts to be the basic in our study of polite communication: assertives (representatives), directives, expressives, performatives.

\section{Speech acts of polite appeal and blessing}

The functional purpose of appeals and blessings is not only to convey different types of information about the communicants, but to create the desired stable emotional attitude towards him or her and to develop a certain pattern of behavior. Persuasive impact of polite communication is based on the combination of rational, emotional, logical and psychological principles.

As a speech act, polite appeal or blessing can perform functions, combining explicit or implicit assertives (conveying information and showing the importance of a certain person) and expressives (influencing attitudes towards the person). At the same time, the pragmatic focus of any polite speech act is directive (promoting a pattern of behavior, following traditional lifestyle, maintaining the stability of the traditional society).
The list of speech actions that different researchers starting with Searle, associate with expressives, includes gratitude, anger, complaint, apology, compliment, flattery, resentment, disapproval, approval, insult, wish, thank, curse, toast, congratulations, dedication, praise, greetings, presentation, invitation, acceptance of thanks and apologies, leave-taking, joy, disappointment, swearing, condolences, regret, reproach. Some of these speech acts can include appeals. Compliment, wish, dedication, praise constitute the elements of speech act of blessing.

Correct understanding of the speech act is not only the immersion into the context of the situation. It is necessary to include the context of a certain communicative style characteristic of a particular civilization and era. For example, in the Middle Ages, everything was immersed in a sense of eternal guilt, and even the name was not signed without the addition of the word "sinner."

\subsection{Functional characteristics of appeals}

In speech, an appealing message performs two basic functions, usually implemented jointly: calling and expressive functions.

In the speech act illocutionary force is determined by semantic function of circulation in speech. It is possible to distinguish the following functions of appeals: 1) vocative (intention is to attract attention of the addressee); 2) deictic (intention is to indicate the addressee); 3) nominative (intention is to name the addressee); 4) social regulation (intention is to reflect the status role ratio of communicators and arrange the speech in a polite way); 5) estimation (intention is to characterize the addressee and the attitude of the speaker to him or her).

Speech acts of polite appeal can be associated with vocatives. These units include a large number of linguistic phenomena and have a very broad meaning. Vocatives include two types of units. The first are interjections, by which people attract attention (Hey!), sometimes with pronouns (Hello, everybody!). The other constitutes a class that includes various kinds of titles, kinship terms, personal pronouns, proper names, emotional and expressive nominations [7].

According to V. I. Karasik, the purpose of vocatives in the language is to perform the appellate function, establishing and maintaining contact between the participants of communication. Attracting the attention of the addressee can be achieved both verbally and nonverbally, so vocatives are a verbal form of attracting the addressee's attention. In their function, vocatives refer to non-informative speech actions (they do not report anything new) and express regulatory, index and emotional content. Regulatory or directive content is associated with the establishment, maintenance and closing the contact, the index content characterizes the psychological state and social status of the speaker, emotional content is supposed to add extra meaning to the speech act [7].

In the story of R. Kipling "Moti Guj - Mutineer" an elephant driver appeals to his clever animal, varying the polarity of the assessment appeals: Light of my heart, 
mountain of might, give ear, said Deesa. I'm going away. But you, fussy old pig, must stay behind and work shall be done for ten days, o delectable one. Warty toad, I hold up your foot, dried mud-puddle ... Be still, hog of the back woods ... O my lord, my king! Jewel of all elephants, lily of the herd, preserve your honored health, be virtuous [8].

Positive appeals the light of my heart, mountain power, my delight, my lord, alternate with negative appeals old boring pig, forest boar and others. It is known that the driver is very attached to his animal. Offensive appeals have meaning of joking, sublimate appeals are ironic. Such intersection of figurative meanings forms a picture of the character's personal style and style of Indians from the point of view of the British colonialists.

\subsection{Functional characteristics of blessings}

Among J. Austin's speech acts, special place is given to bahabitives: formulas of social etiquette, usually expressing reactions to the behavior of other people, for example: congratulations, apologies, I take my words back, etc. Behabitives include the reaction to other people's behavior and on the turns of their fates. They also include the state of relations in the past or in the future and the explicit expression of this relation. Examples of these speech acts are: apologizes, congratulations, praises, challenges and others having performative function. Here we can find accordance with the speech acts of blessings.

According to J. Austin's theory [3], the verbs bless and wish are included in the behabitive subclass of performative verbs. It includes the verbs with positive and negative connotations. Positively connoted performative verbs apologize, bless, thank, condole, congratulate, sympathize, toast, wish are associated with phatic communication or rituals. So, blessings are essential elements of the rituals of thanking, congratulation, showing sympathy, toasting, greeting, leave-taking.

The relationships between linguistic meaning and the functions of blessing formulas can be quite complex. Some specific relationship between the lexical meaning and pragmatic functions of blessings were named by the linguists:

1. A blessing is free from its propositional content, it is idiomatized and grammaticalized, and serves as a verbal routine, a part of a verbal ritual;

2. It is partially free from referential meaning and functions as an element of a verbal ritual;

3. A blessing formula retains its lexical meaning and serves as a blessing proper in communication.

4. Certain blessing formulas serve as substitutes for the performative acts realized by the performative verbs [9].

\section{The peculiarities of polite appeals and blessing in Indian English}

English formulas of politeness are of great importance in India, since the local Indian languages (Hindi, Bengali, Gujarati, Urdu, Tamil and others) retain many options for the linguistic and extralinguistic expressions of politeness.
Knowledge of the English language is an indicator of a person's good education and as a rule it gives a higher social status. It implies institutional, systematic relations based on norms (external towards direct social interaction) [10].

For all territorial regions of India and for all major social levels, there are some forms of informal communication and polite formulas in English. At the same time there is a big difference between the spoken and literary variety with the emerging norms of Indian English, different from the standard British. The wide variety of functions contributes to the significant penetration of different varieties of English into all social sectors of society in modern India [11].

\subsection{The peculiarities of polite appeal in Indian English}

Many means - linguistic and extralinguistic - have their own specific functions in the expression of politeness in certain speech acts, for example, the use of certain pronouns, honorifics, special honorary titles. In many languages of the Indian subcontinent status and solidarity in social communication interact with each other in various ways, whereas in many European languages this balance is destroyed because the criterion of solidarity is used both vertically and horizontally [12]. That is, the differences are reduced at the vertical level, just like age, role and sex differences at the horizontal level.

Appeals are implemented on the levels of formal and informal communication. They are characterized by special importance for communication because they have an expressive function that allows express the social status, personal attitude of the speaker to the person he or she refers.

\subsubsection{Use of pronouns in polite appeals}

Very often an introductory or an initial formula of appealing to a well-known or unknown person includes a pronoun. Use of pronouns emphasizes status (relatively large social distance) and solidarity (intimacy, membership in a group), which are two main aspects of social relations influencing the choice of the appeal form in any language.

Many languages (for example, French, German, Hindi, Spanish, Russian) have the form of a second person pronoun, which is grammatically unique and is used for reference to a younger or a lower status person, also a close relationship (T-pronoun). There is also another second person pronoun that is grammatically plural, honourable or both, and is used for a person older, higher in status or not close in relationship (V-pronoun).

R. Brown and A. Gilman revealed the law which was linguistically universal in all the languages they had studied: the pronoun forms used while referring from the higher status to the lower status person, also used when referring horizontally to close ones, and vice versa. R. Brown noticed a tendency in the modern European languages to avoid the non-reciprocal use of second person pronouns, using only the dimension of solidarity 
in relation to the choice of a pronoun [13]. Thus, there is an increasing tendency to appeal to all relatives, regardless of status, using T-pronoun, and to all strangers with V-pronoun. A similar process occurred in the Russian language after the 1917 revolution due to changes in the reflection of social classes in the language [14].

In the Punjabi language, as well as in Hindi, there is a form of appeal that corresponds to T-pronoun Toon, and V-pronoun Tusi. People, including parents and older relatives, and even spouses appeal to each other mostly using V-pronoun, rarely switching to T-pronoun - this is considered more romantic. At the same time, appealing to all younger people or wishing to express disrespect towards the interlocutor, they use T-pronoun.

In standard British English, there is no difference in the number of pronouns for the second person. People use for both V-pronoun and T-pronoun one and the same unit you. It is not suitable for traditional appeal in local Indian lingua-cultures, where there is a great distinction between the appeals to communicators equal and not equal in social standing or age.

In Indian English, the phrase you people is used when referring to more than one person. It does not mean downgrading, racial connotations; this is a simple translation of aap log or tum log from Hindi.

Thus informal style of communication demands using local languages pronouns that were borrowed to Indian English. These pronouns have various functions, designating people in the singular and in the plural, expressing respectful attitude towards the interlocutor.

\subsubsection{Use of respectful honorifics}

Respectful appeals with honorifics are the most common ways to display politeness towards the person. In standard English, there are no special pronouns or markers to show respect, only nouns like sir. In Indian English, units such as honorable sir, respected sir, or their expressions in local languages are used very often. In India, to address visiting (from the UK and the USA) professors, there is a special polite formula Respected Sir Professor X.

Using polite appeals is a universal form of etiquette contact for people with equal or unequal status. In standard English, appeals are marked only with a rising status vector. The units, which are markers of respectfulness, are used before the names of various people and gods. Etymologically they denote the concepts of "senior" (sir - senior) and "master" (mister).

In Indian English honorifics have the same meanings. Typical for India unit sahib ('lord, master') is added, as a rule, to Muslim names, but not exclusively [15]. Respectful suffix $j i$ may be used with both men and women before or after the name or a nomination word. Example: Please call a taxi for Gupta-ji [16].

There is also a special prefix Shree / Shri when referring to men, Shreemati / Shrimati - to women. Example: Shreemati Das Gupta.

The use of $s a a b$ or $s a a b j i$ is popular. However, the units $s a a b$ and $j i$ have different functions. The word $j i$ ('respected') was originally used as an appeal to a senior at home, for example, ji papa, dadaji, to a senior by age person ji sir, uncle ji. Saab is an appeal to the boss, for example, boss saab / sahib is an explicit expression of a higher social status of the interlocutor. The expression boss saab is a hybrid phrase, where the first element comes from standard British English, and the second comes from Arabic, originally meaning 'owner, boss'. Formerly this is a polite address to a European person in colonial India.

Often when appealing to an unknown person in India, the terms of family relationships are used. This method is sometimes used when referring to people who are not related to the speaker. To mitigate the request or to avoid refusal in many Indian and other New English languages of Southeast Asia, it is customary to contact the addressee as mother, brother, sister, friend. Informal speech, as a rule, demands the use of appropriate units originated from the local Indian languages. For example, an appeal to an elderly Indian woman is mataji. The appeal bahen 'sister', refers to a Hindu woman with the age from young to not old yet.

For demonstration of respect and courteous treatment to a stranger, for example, in a local store, language units having in their meaning an element of "older by age" are used. For example, veerji is an appeal to a person of equal status in Punjabi, meaning 'older brother', didi is an elder sister, bhabi ji is 'wife of an elder brother'. Within the families, veerji and didiji are the usual appeals of the younger children to the elders, while the younger ones are called only by their names.

In many languages of the world, including Indian English, appeals such as uncle, aunt to strangers who are older than speaker are accepted. For reference to an older woman, there is a hybrid expression aunty ji, despite the fact that mothers' and fathers' sisters are called differently (mummy ji and pukha ji, respectively).

There is also popular use of the unit baba as an appeal. $B a b a$ is considered to be a synonym for the English word buddy (comrade): No Baba, just try and understand, I can t come today [16]. Using of this word implies much respect as it is understood as an element of friendly communication between men and never between women.

Thus, the use of polite appealing formulas in Indian English is greatly influenced by age and gender restrictions that are characteristic for traditional societies. The nomination of kinship as a reference has the function of solidarity of the participants in communication and reducing of social distance; the use of respectful pronouns and special honorifics - the function of emphasizing of social status and increasing of social distance between the participants of communication. The most common polite appeals in Indian English include units with the meanings of "senior, master" and nominating family relationships. The units can be classified into two unequal grammar groups - honorific prefixes and nouns.

\subsection{The peculiarities of blessings in Indian English}

Blessing is typical of Oriental cultures, including India, as one of the forms of polite communication. The speech act of blessing includes a large reservoir of various good wishes and compliments and is used to demonstrate the good disposition of the speaker to the interlocutor. Blessing is a ritualized, religious act, where the speaker 
having a higher social status declares benediction upon another person wishing future life with protection from harm, happiness and prosperity. The act of blessing is conferred by the higher power on which the speaker calls.

Good wishes are common for British English culture. Such formulas as God bless you, May God bless you are acceptable in many situations and are used by elders to bless young people. In Indian English lingua-culture blessings are essential elements of the rituals of thanking, expressing condolences, congratulations, showing sympathy, toasting, wishing a good journey.

The Indian English language is characterized by the wishes of god's help in affairs, prosperity in the material or social sphere, long life, good children (Live to see your great grandsons). At the same time, the wish of gods' help and prosperity is a universal value, characteristic also for standard English, while the wish of good children is specific for Indo-English linguistic culture.

Let us give examples of blessings that are specific to Indian culture and are closely related to the traditions of the Indian people, from Rama Mehta's novel Inside the Haveli [17].

1. May you have many sons and may you always wear red. May you live in your husband's shadow for a hundred years.

These blessings are typical for Indian English used as a lingua franca language. Only participants familiar with Indian culture understand the meaning of these statements, indicating that women always wish to have many sons and not be widowed, and red is the colour of married women. These blessings contain the main values of Indian women in the traditional lingua-culture which deal with the family. The wish of a married woman in hot climate of India to live in the shadow of her husband is interpreted as 'to be very happy, to have protection of her spouse throughout her life'. Being fertile and producing many sons is a positive characteristic for a woman, since sons are a support in old age and successors of the clan. It should be pointed out that this kind of blessings can only be addressed to women, never men, which emphasizes the dependent role of women in India as a heritage of the colonial era.

Using the formulas of greetings and blessings simultaneously in one speech act is characterized by a high degree of ritualization [18].

In the following passage, greetings are borrowed directly from the Punjabi language. In this case, the appeal functions as a precondition for blessing and both formulas are parts of the speech act of leave-taking before bedtime, which are included in the class of expressive speech acts. 2. She bent her head to receive her mother-in-law's blessing. 'Sat Sri Akal.'

'Sat Sri Akal,' replied Sabhrai lightly touching Champak's shoulder.

'Sat Sri Akal,' said Sher Singh.

'Live in plenty, Live a long age,' replied Sabhrai taking her son's hand and kissing it.

'Sleep Well' [18].

Formula Sat Shri Akaal or Sat Sri Akal is a Sikh greeting, where the unit Sat means 'truth', Sri 'great', Akaal 'Lord'. The complete expression "Jo Bole So Nihaal, Sat Sri Akaal" means 'Blessed is the person who says 'God is Truth'" [19]. The author of the work R. Mehta uses the ritual formula of greeting common among Sikhs for both speech acts of greetings and leave-taking. The stereotypical response to this expression is a blessing from the part of a senior person. Taking into account the context of the passage, one should pay attention to the difference in the reaction of the mother communicating with the daughter-in-law and with the son. The response to the son contains a more explicit expression of respect and love: a welcome formula, a blessing (wishing a long life), a hand kiss. In relation to the daughter-in-law, the mother-in-law is limited to a stereotypical greeting, lightly touching the shoulder with a wish for good sleep.

Thus, blessings play an important role in informal communication. Blessings acquire lingua-cultural value within the framework of a sociocultural norm or institution. They are highly conventional formulas of polite communication and indicate the relationship between the interlocutors. Blessings are associated with speech acts of greeting, leave-taking, thanksgiving. As well as compliments, blessings have the functions of support, solidarity.

\section{Conclusion}

Formulas of politeness and respect are important for successful communication in every speech society. The order of application of these units is different in all cultures. For Indian English, polite communication has an explicit manifestation, both for grammatical structure and for vocabulary and syntax.

Thus, studying the formulas of politeness in Indian English, as in many new English languages, it is necessary to understand the lingua-cultural specificity of this speech community. Each individual speech act correlates with different values and a set of norms that define the choice of certain formulas of communication. Markers of politeness in linguistic interaction exist in speech communities to reduce conflicts and maintain rituals in the traditional society.

Appeals as expressive speech acts always have the function of expressing the attitude of the speaker to the listener. The use of polite appeals in Indian English is greatly influenced by age and gender restrictions and traditional stratification of social and family relations. Since the days of colonial dependence, speech polite formulas and clichés came from local Indian languages into Indian English.

Being structurally, semantically and pragmatically different, blessing formulas perform a variety of functions in different registers, but mostly informal. The standard forms of blessings can be considered as the bearers of group traditional culture, individual and person values. The use of blessings mainly belongs to communication strategies, mostly an avoidance one. 


\section{References}

1. Ch. A. Ferguson, Conversational routine: explorations in standardized communication situations and prepatterned speech 21-35 (Mouton Publishers, The Hague, Paris, N. Y, 1981)

2. S. L. Tsohatzidis, Speech act theory: some current options, Intercultural Pragmatics, 7(2), 341-362 (2010)

3. J.L. Austin, How to do things with words (Oxford University Press, Oxford, 1975)

4. J.R. Searle, Classification of illocutionary acts, Language in Society 5 (01), 1-23 (1976)

5. G.G. Pocheptsov, Pragmatic interpretation and planning of discourse 3-6 (Publishing House of PSPII, Pyatigorsk, 1991)

6. G.G. Pocheptsov, Semantics and pragmatics of syntactic unity 52-68 (KSU publishing, Kalinin, 1981)

7. V. I. Karasik, Language of social status (VSPU Publishing, Volgograd, 1992)

8. R. Kipling, Life's Handicap (Adamant Media Corporation, Boston, 2002)

9. W. Boeder, The South Caucasian languages, Lingua 115, 5-89 (2005)

10. I.V. Palashevskaya, E.A Kurchenkova, V.V. Leontiev, Status positions of courtroom discourse participants. Advances in Social Science, Education and Humanities Research (ASSEHR) 97, 209-213 (2017)

11. E.A Kurchenkova, Functional diversities of Indian English. Izvestija VGSPU 10, 104-108, (2014)

12. D. I. Slobin, Some aspects of the use of pronouns of address in Yiddish. Word 19, 193-202 (1963)

13. R. Brown, A. Gilman, Style in Language 253-276 (MIT Press, Cambridge, 1960)

14. G.G. Corbett, Address in Russian. Journal of Russian Studies 31, 3-15 (1976)

15. J. Crowther, Oxford Advanced Learner's Dictionary of Current English. Fifth Edition with a Special Supplement of Indian English (OUP, Oxford,1996) 60

16. S. Rushdie, Midnight's children (Random House Trade Paperbacks, NY, 1980)

17. R. Mehta, Inside the Haveli (Einemann, New Delhi, 1977)

18. Y. Kachru, Speech acts in World Englishes: toward a framework for research, World Englishes 10, 299306 (1991)

19. S. P. Singh Sandhu Matta, My mother tongue, Quora, Retrieved from: https://www.quora.com/What-isthe-meaning-of-Punjabi-greet-Sat-Sri-Akal (2016) 